\title{
Simulation-based approach to assess occupancy-adaptability of buildings
}

\author{
William O’Brien ${ }^{1}$, H. Burak Gunay ${ }^{1}$, Mohamed Ouf ${ }^{2}$ \\ ${ }^{1}$ Department of Civil and Environmental Engineering, Carleton University, Ottawa, Canada \\ ${ }^{2}$ Department of Building, Civil and Environmental Engineering, Concordia University, Montreal, Canada
}

\begin{abstract}
Office buildings rarely encounter near-capacity occupancy, despite the majority of building energy codes and design processes assuming as much. The hypothesis of this paper is that current occupancy schedules have the serious risk of misleading decision makers away from technologies that allow buildings to adapt to partial occupancy. To test the hypothesis and demonstrate alternative methods to model occupancy, this paper examines open-plan lighting control schemes and demand-controlled ventilation (DCV) under different occupancy scenarios using detailed building simulations. The results show that the benefit of DCV may be underestimated by a factor of two under full occupancy assumptions. Meanwhile, lights may be turned on two times longer than occupants are present if current standard schedules are used to guide lighting control zone sizes. Without technologies and operating strategies that adapt to partial occupancy, high-performance buildings will not reach their potential.
\end{abstract}

\section{Introduction}

One of the prominent applications for building performance simulation (BPS) is code compliance, whereby a design building model's annual energy use is required to meet or exceed that of a reference building model that complies with prescriptive requirements. It is routine practice to address non-compliant designs by adjusting the design to achieve code compliance. In most building energy codes and standards (e.g., ASHRAE Std. 90.1 and Canada's National Energy Code for Buildings (NECB)), occupant-related assumptions are modelled using hourly schedules for weekdays and weekends. The schedules are normally provided by the code, though some codes allow the modeller to modify the defaults if better knowledge is available. Abuimara, O'Brien, Gunay, Abdelalim, Ouf and Gilani (2018) reported that modellers commonly use the standard schedules to inform design (e.g., at design charrettes), even when schedules are unrestricted, because modellers aim to avoid the liability of deviating from the norm. Part of modellers' challenge is that there is tremendous uncertainty about occupancy particularly for buildings that will be leased to unknown tenants. Regardless, modellers are normally required to use the same schedules for both the reference and design building models with the implicit assumption that the design does not affect occupancy and occupant behaviour.
The standard occupancy schedules for offices typically assume peaks of 90 to $95 \%$ of capacity during the middle of weekdays and occupant densities of approximately 20 $\mathrm{m}^{2}$ per person. Figure 1 shows occupancy schedules for several North American standards and codes and large dataset of 629 motion sensors from Duarte, Van Den Wymelenberg and Rieger (2013). In general, the literature is reporting much lower occupancy than schedules suggest (Davis III and Nutter 2010, Gunay, O'Brien and Beausoleil-Morrison 2015). This is thought to be in part because the schedules were designed to be conservative, but also because the schedules were built from data from a previous generation. Since the 1980s, there has been a significant change in the workplace, such as teleworking, prevalence of information and communication technology, and more flexible work hours (Hood, Nagy, Lister and Brand 2017). Moreover, there is significant diversity between occupants and spaces, and over time (Davis III and Nutter 2010, Bennet and O'Brien 2017, O'Brien, Gunay, Tahmasebi and Mahdavi 2017). Mean profiles, such as those presented in Figure 1, conceal the diversity of the raw data.

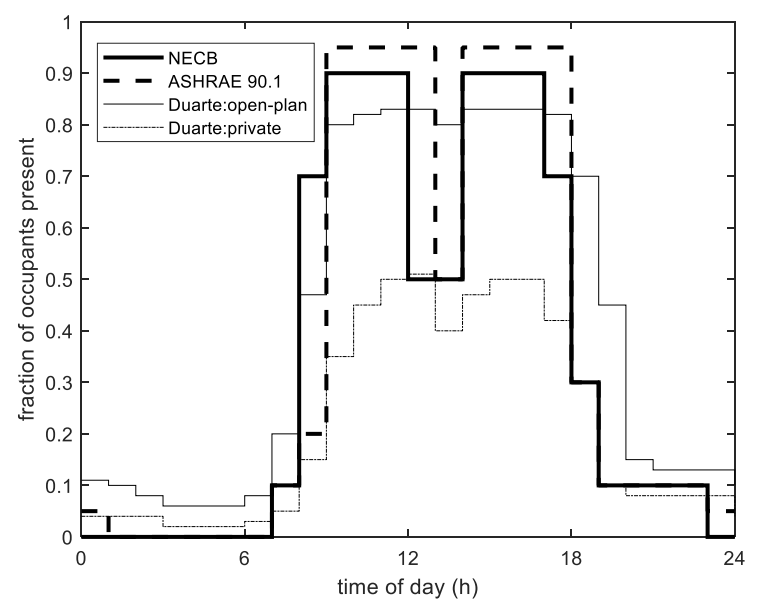

\section{Figure 1: Comparison of standard and measured} occupancy schedules

Buildings continue to be designed -and often operatedunder the assumption of full-occupancy (Duarte, Van Den Wymelenberg et al. 2013). And more consequentially, typically highly-conservative assumptions are made about occupancy rather than focusing on design features that allow a building to perform well under a wide range of occupancy conditions (O'Brien, Gaetani, Gilani, Carlucci, Hoes and Hensen 2016). 
The hypothesis of this paper is that current occupancy schedules underestimate the benefit of occupancyadaptive technologies because of the common practice to consider only one occupancy scenario with near-full occupancy. This paper is expected to lead to improved design processes and building codes that consider partial occupancy scenarios for making design decisions.

Two of the key technologies that allow buildings to adapt to partial occupancy are occupancy-based lighting controls and demand-controlled ventilation (Galasiu, Newsham, Suvagau and Sander 2007, Liu, Zhang and Dasu 2012). Occupancy-based lighting, which is typically mandated in most energy codes (e.g., ASHRAE Std. 90.1 and NECB), is focused on controlling lights to be on only when a space is occupied unless doing so compromises safety. Demand controlled ventilation seeks to reduce outdoor air supply rates in partially occupied or vacant spaces. All occupancy-adaptive controls require some direct or indirect measurement of occupancy. Many occupancy detection and measuring technologies have emerged in the past decades (e.g., WiFi, video and computer vision, $\mathrm{CO}_{2}$, etc.) (Shen, Newsham and Gunay 2017). However, occupancy sensing is beyond the scope of this paper; buildings controls are currently simulated under the assumption that occupancy is known.

While extensive investigations of building control strategies have been researched (Nassif 2012, de Bakker, Aries, Kort and Rosemann 2017), the major gap is considering partial and variable occupancy in conjunction with these technologies in the context of design decisions and code requirements. Galasiu, Newsham, Suvagau and Sander (2007) demonstrated 35\% energy savings through occupancy-based lighting controls in open-plan offices. de Bakker, Aries, Kort and Rosemann (2017) observed that the majority of open-plan lighting studies are based on field studies rather than simulation; this is thought in part to be a result of the challenges of modelling and simulating such spaces, considering variable occupancy.

Previous field and simulation studies have shown DCV to have energy savings potential on the order of 2 to $30 \%$ (Fisk and De Almeida 1998, Hong and Fisk 2010, Nassif 2012). The savings are greatly dependent on occupancy, climate, and technology. For instance, presence of dedicated outdoor air systems (DOAS) means that outdoor air supply rate can be completely controlled based on occupancy; whereas typical VAV systems must also consider air supply for conditioning spaces. In general, the buildings that benefit most from DCV: are in extreme climates with high heating and cooling loads; have high nominal occupant density (e.g., theatres); and frequently experience partial occupancy conditions.

A further building operating strategy to address partial occupancy is hot-desking or hotelling, which mitigates the issue of partial occupancy and occupant diversity by having occupants schedule a desk for a given day rather than having a fixed desk. However, this approach is more of an architectural and management issue and is not addressed in the current paper.
Previously, occupancy models have evolved to be quite advanced, considering occupants' stochastic nature and the desire to model individuals rather than populations (Page, Robinson, Morel and Scartezzini 2008, Tahmasebi and Mahdavi 2015). Schedule-based models treat occupants as populations and do not allow individuals' presence and location to be predicted without further steps. The majority of recent research on occupant modelling has focused on improving accuracy and capabilities of the models (Schweiker, Haldi, Shukuya and Robinson 2012, Tahmasebi and Mahdavi 2015). However, relatively little research has focused on practical applications of occupant models (Gaetani, Hoes and Hensen 2016, Gilani, O’Brien, Gunay and Carrizo 2016). Indeed, few practitioners go beyond simple schedule-based modelling approaches (O'Brien, Gaetani, Gilani, Carlucci, Hoes and Hensen 2016).

The remainder of the paper starts with a detailed description of the building and occupant modelling methodologies used to assess lighting control zone sizes and demand-controlled ventilation. Next, results of the simulations are presented and discussed. Finally, the paper concludes with some general recommendations for how designers and building energy code committees could better incorporate uncertain and variable occupancy into their respective professional activities.

\section{Methodology}

Two distinct modelling approaches were used for the lighting and DCV analysis, as summarized in Table 1 . The common element is that both analyses are aimed at evaluating technologies at lower-than-standard occupancy to determine whether they are more favourable than for standard occupancy. This section presents the modelling approach for lighting, followed by DCV.

Table 1: Summary of modelling approaches.

\begin{tabular}{|c|c|c|c|}
\hline Topic & $\begin{array}{c}\text { Building } \\
\text { scale }\end{array}$ & $\begin{array}{c}\begin{array}{c}\text { Building } \\
\text { model }\end{array} \\
\end{array}$ & $\begin{array}{c}\text { Occupant } \\
\text { model }\end{array}$ \\
\hline Lighting & $\begin{array}{l}\text { One very } \\
\text { large } \\
\text { open-plan } \\
\text { office }\end{array}$ & $\begin{array}{l}\text { A simple grid } \\
\text { of cubicles } \\
\text { using } \\
\text { MATLAB }\end{array}$ & $\begin{array}{l}\text { Page, Robinson, } \\
\text { Morel and } \\
\text { Scartezzini } \\
\text { (2008) model } \\
\text { within schedule } \\
\text { inputs as below }\end{array}$ \\
\hline DCV & $\begin{array}{l}\text { A three- } \\
\text { storey } \\
\text { office } \\
\text { building }\end{array}$ & $\begin{array}{c}\text { A detailed } \\
\text { EnergyPlus } \\
\text { v8.7 model }\end{array}$ & $\begin{array}{l}0.4,0.6,0.8, \text { and } \\
1.0 \text { times the } \\
\text { NECB } \\
\text { occupancy } \\
\text { schedule }\end{array}$ \\
\hline
\end{tabular}

\section{Lighting modelling approach}

Lighting can be modelled as quasi-steady state because controls and propagation of light can be considered instantaneous in the realm of annual simulations. A very large open-plan office was modelled as a two-dimensional square grid (Figure 2). Corridors and other such spaces are only implicitly modelled and assumed to be part of the cubicle grid and corresponding overhead lighting system. A three-dimensional array was used to store simulation data for each of occupancy and light state (the third 
dimension is time, in 5-minute timesteps for four weeks). Lighting controls, discussed in detail later, govern the light state over each cubicle in groups.

For assessing lighting controls in an open plan office, it is critical to have a spatial component of occupancy simulations (i.e., know which cubicle(s) are occupied) and to treat occupants as independent agents. Meanwhile, the lighting state and corresponding energy use is dependent on where the occupied cubicles are positioned with respect to each other. A stochastic modelling approach reflects the notion that occupants in a real office environment typically arrive and depart in a nondeterministic manner. The current modelling approach assumes that occupants are independent of each other (e.g., neighbouring occupants do not necessarily share schedules or try to avoid each other).

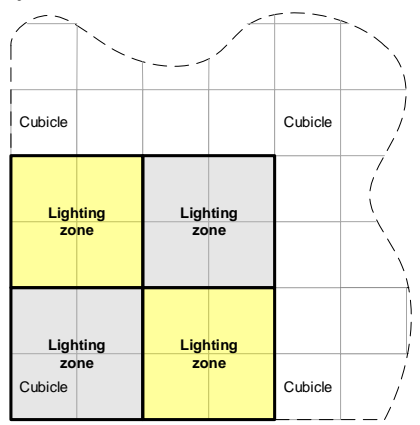

Figure 2: Example lighting control zone scheme with four cubicles within each zone

For every timestep, each occupant was modelled independently and assumed to either be present or absent (away from the building) using the Page, Robinson, Morel and Scartezzini (2008) model. The input schedules for the model was varied to consider different scenarios using multipliers of $0.4,0.6,0.8$, and 1.0 times the weekday NECB occupancy schedule (Figure 3). A mobility parameter value of 0.1 was used; this specification indicates the probability that the occupancy state changes at a given timestep. Refer to Page, Robinson, Morel and Scartezzini (2008) for details. Upon initial simulations, it was verified that this stochastic model results in mean occupancy value of within $10 \%$ of the input schedule (i.e., from NECB) for each simulated week. Note that the NECB office schedule does not have occupancy on weekends. Using this assumption in the current work is conservative because small lighting control zones particularly benefit from the sparse occupancy expected on weekends.

Lighting control zones sizes of between 1 and 25 cubicles were modelled. The lighting control zones perfectly coincide with cubicles, e.g., as shown in Figure 2, which represents an optimal geometry for this modelling approach. de Bakker, Aries, Kort and Rosemann (2017) noted that such a configuration is critical to achieve energy savings through advanced controls. NECB requires the lighting control zones to be no larger than 250 $\mathrm{m}^{2}$ when they are turned on and no larger than $50 \mathrm{~m}^{2}$ when they are turned off. This scenario is simulated, though all other results assume the areas are equal to reflect common practice. The model is based on cubicles rather than floor area, so each cubicle (and associated corridors) was assumed to be $10 \mathrm{~m}^{2}$, such that the $250 \mathrm{~m}^{2}$ limit corresponds to 25 cubicles.

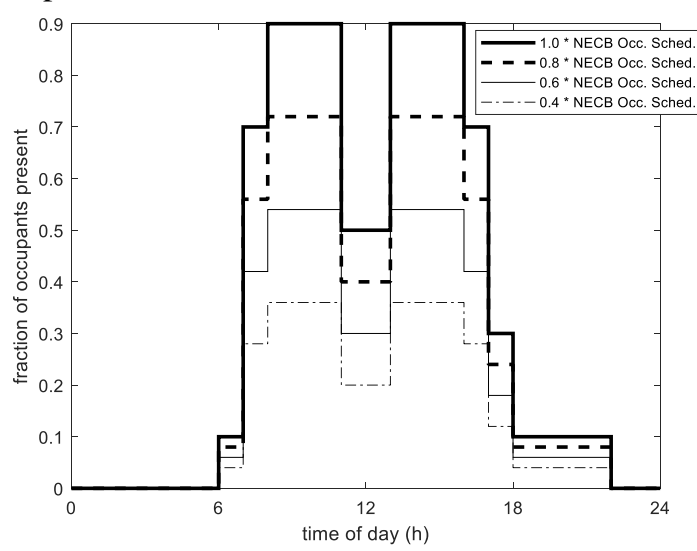

Figure 3: Input schedules for occupancy model for the lighting analysis and occupancy schedules for the DCV analysis

Lighting controls were modelled to follow NECB requirements and standard practice, as follows. As long as one occupant is at a cubicle in the lighting control zone, the lights for that control zone are on. Their work activities are assumed to require direct overhead lighting. While NECB requires lights to be manually turned on to exploit possible daylight or other ambient light, the space is assumed to be very large and not have daylight. Lighting is assumed to be aimed at the workplane below and not into adjacent lighting control zones. The lighting control zones are assumed to be equipped with occupancy sensors such that they can detect vacancy with perfect accuracy. The lights in the control zone turn off once 20 minutes of vacancy has elapsed. However, arrival of an occupant to that zone restarts the count.

The limitation of the current modelling approach is that it neglects illuminance of a particular cubicle's workplane from adjacent lighting. As long as the lighting is directed downwards, the space is not too high, and occupants have an expectation for full lighting conditions, this assumption is expected to be reasonable. Reinhart and Voss (2003) found that only two of ten occupants would not turn on lights if the workplane illuminance is below 50 lux, though that study focused on daylighting.

The original research question is whether near-full occupancy assumptions underestimate the benefit of small lighting control zones. Thus, the results section shows a systematic comparison of the four occupancy scenarios against light control zones of between 10 and $250 \mathrm{~m}^{2}$ ( 1 and 25 cubicles). Because daylight was not considered, there is not a seasonal effect that necessitates annual simulations. Therefore, simulating four weeks of was found to be plenty for the results to consistently converge.

\section{Demand-controlled ventilation modelling approach}

Demand-controlled ventilation analysis requires a more integrated and whole-year model because of the impacts of occupancy and climate on heating, cooling, ventilation, and fan energy. However, unlike for the lighting analysis, 
the exact location of occupants is not necessary since ventilation is only controlled at the system (e.g., floor or building) level.

Table 2: Summary of building model used to assess DCV

\begin{tabular}{|c|c|c|}
\hline \multirow[t]{5}{*}{ Geometry } & Gross dimensions & $\begin{array}{c}49.9 \mathrm{~m} \text { (east-west } \\
\text { axis) } \times 33.3 \mathrm{~m} \\
\text { (north-south axis) } \\
\times 10.7 \mathrm{~m} \text { height } \\
\end{array}$ \\
\hline & $\begin{array}{l}\text { Total floor area } \\
\left(\mathrm{m}^{2}\right)\end{array}$ & 4982 \\
\hline & Storeys & 3 \\
\hline & Thermal zones & $\begin{array}{l}15 \text { ( } 4 \text { perimeter } \\
\text { zones and } 1 \text { core } \\
\text { zones per storey) }\end{array}$ \\
\hline & $\begin{array}{l}\text { Window to wall } \\
\text { area ratio (WWR) } \\
\text { for all four facade } \\
\text { orientations }\end{array}$ & $40 \%$ \\
\hline \multirow{3}{*}{$\begin{array}{c}\text { Building } \\
\text { Envelope U- } \\
\text { value } \\
\left(\mathbf{W} / \mathbf{m}^{2} \mathbf{K}\right)\end{array}$} & Roof & 0.183 \\
\hline & Walls & 0.247 \\
\hline & Below grade floor & 0.757 \\
\hline \multirow{2}{*}{$\begin{array}{c}\text { Window } \\
\text { properties }\end{array}$} & U-factor & 2.2 \\
\hline & SHGC & 0.6 \\
\hline $\begin{array}{l}\text { Infiltration } \\
\text { Rates }\end{array}$ & $\begin{array}{l}\text { Nominal flow per } \\
\text { exterior surface } \\
\text { area }\left(\mathrm{m}^{3} / \mathrm{s}-\mathrm{m}^{2}\right) \\
\end{array}$ & 0.00025 \\
\hline $\begin{array}{l}\text { HVAC air } \\
\quad \text { loop }\end{array}$ & \multicolumn{2}{|c|}{$\begin{array}{l}\text { Each floor is served by a separate air } \\
\text { handling unit. The AHU operational } \\
\text { hours are from } 5 \text { AM to } 8 \text { PM for } \\
\text { weekdays Otherwise, the AHU is } \\
\text { switched off. The building relies on free } \\
\text { cooling when the outdoor temperature is } \\
\text { between } 1 \text { and } 20^{\circ} \mathrm{C} \text {. }\end{array}$} \\
\hline $\begin{array}{c}\text { Zone HVAC } \\
\text { system }\end{array}$ & \multicolumn{2}{|c|}{$\begin{array}{l}\text { Each zone is equipped with VAV box } \\
\text { with reheat coil for providing heating and } \\
\text { cooling to the space. A baseboard heater } \\
\text { is used for maintaining setback } \\
\text { temperatures in the heating season when } \\
\text { the AHU is not operated. }\end{array}$} \\
\hline $\begin{array}{c}\text { Nominal } \\
\text { outdoor air } \\
\text { flow when } \\
\text { AHUs are on }\end{array}$ & $\begin{array}{l}\text { Outdoor air } \\
\text { flow/person }\left(\mathrm{R}_{\mathrm{P}}\right) \\
\text { Outdoor air } \\
\text { flow/zone floor } \\
\text { area }\left(\mathrm{R}_{\mathrm{A}}\right) \\
\end{array}$ & $\begin{array}{c}0.0025 \mathrm{~m}^{3} / \mathrm{s}- \\
\text { person } \\
0.0003 \mathrm{~m}^{3} / \mathrm{s}-\mathrm{m}^{2} \\
\text { (ASHRAE Std. } \\
\text { 62.1) } \\
\end{array}$ \\
\hline Heating plant & \multicolumn{2}{|c|}{$\begin{array}{l}\text { Natural gas boiler with an efficiency of } \\
83 \%\end{array}$} \\
\hline Cooling plant & \multicolumn{2}{|c|}{$\begin{array}{c}\text { One electric chiller EIR with reference } \\
\text { COP of } 4.5 \text { and a single speed cooling } \\
\text { tower }\end{array}$} \\
\hline \multirow[t]{2}{*}{$\begin{array}{c}\text { Thermostat } \\
\text { settings }\end{array}$} & Occupied & $\begin{array}{l}22^{\circ} \mathrm{C} \text { heating and } \\
24^{\circ} \mathrm{C} \text { cooling }\end{array}$ \\
\hline & Unoccupied & $\begin{array}{l}18^{\circ} \mathrm{C} \text { heating and } \\
28^{\circ} \mathrm{C} \text { cooling }\end{array}$ \\
\hline $\begin{array}{c}\text { Peak } \\
\text { occupant } \\
\text { density } \\
\end{array}$ & \multicolumn{2}{|c|}{0.05 occupants $/ \mathrm{m}^{2}$} \\
\hline $\begin{array}{c}\text { Lighting } \\
\text { power density }\end{array}$ & \multicolumn{2}{|c|}{$8.8 \mathrm{~W} / \mathrm{m}^{2}$} \\
\hline $\begin{array}{c}\text { Equipment } \\
\text { power density }\end{array}$ & \multicolumn{2}{|c|}{$7.5 \mathrm{~W} / \mathrm{m}^{2}$} \\
\hline
\end{tabular}

To simulate the impact of DCV on energy savings for different occupancy scenarios, an archetypical cocompliant three-story office building was modelled. The building and model specifications are summarized in Table 2. EnergyPlus version 8.7 was used and the building was simulated in Toronto, Canada using the newer CWEC file, which covers typical years from 1998 to 2014.

Without DCV, the building is ventilated to achieve the ASHRAE Standard 62.1 rates between 7AM and 8PM. When DCV is operated, the outdoor air rate is precisely controlled to the rate in Equation 1 to comply with ASHRAE Standard 62.1-2016 (ASHRAE, 2016).

$$
V_{b z}=2.5 \mathrm{~L} / \mathrm{s} / \text { person } \times N+0.3 \mathrm{~L} / \mathrm{s} / \mathrm{m}^{2} \times A
$$

where $V_{b z}$ is the outdoor air required to be delivered to the breathing zone, $N$ is the number of occupants in the space, and $A$ is the floor area of the zone. Note that the ventilation effectiveness was assumed to be $100 \%$, typical of an entrainment ventilation with no short circuiting.

Unlike for the lighting analysis, the NECB (and three additional lower schedules in Figure 3) were used directly. This simpler approach is justified by the fact the finding from Gilani, O'Brien and Gunay (2018) indicating that results of agent-based modelling converges on an average occupant for larger buildings (e.g., the current one). The modelled occupant density was 0.05 per $\mathrm{m}^{2}$. Fractional occupants were permitted. A limitation to this approach is that all zones are assumed to be uniformly occupied with regards to density. Since the outdoor air fraction (\%OA) is controlled at the airhandling unit level, non-uniform occupant density would require the \%OA to be high enough to meet the most occupied zone.

\section{Results and Discussion}

This section first presents preliminary results of the simulations to illustrate their functionality, followed by the detailed results and discussion.

\section{Lighting analysis results}

In the case of the lighting simulation with four cubicles per zone, two instances were extracted as examples. Table 3 shows two points in time of the occupancy and corresponding light state. Note that because of the controls, the lights are on if at least one occupant was present within the lighting control zone during the past 20 minutes. Thus, during periods with lots of occupant departures (e.g., at 4 PM), many of the lights are on above empty groups of cubicles. At $7 \mathrm{PM}$, in this case, eight times more cubicles are illuminated than occupied.

Next, Figure 4 shows the four-week simulation results of all occupancy scenarios and lighting control zones sizes. Several key values are annotated, including the lighting energy if the standard schedule with and without an NECB credit for vacancy controls is added. The lighting use for the scenario with a different sized lighting on and lighting off control zone size (as per NECB requirements) is also shown. The results are expressed as the mean annual fraction of lights on, which can be directly converted to energy if this value is multiplied by the study period duration and the installed lighting power. 
In general, the results show that at 25 cubicles per lighting control zone, the annual lighting fraction is between 0.47 and 0.51 regardless of the occupancy scenario. This is because the odds of a completely vacant 25 -cubicle zone are similarly low during working hours. Moreover, there is minimal incremental benefit to reducing the control zone size from 25 cubicles, though this benefit is slightly higher for lower occupancy scenarios. However, as the control zone size decreases from 25 cubicles, the lines representing each occupancy scenario diverge significantly. The lower occupancy scenarios, in particular, greatly benefit from smaller lighting control zones. Only as lighting control zones approach one cubicle does the lighting use properly reflect the occupancy level. Energy savings from reducing the lighting control zones from 25 to one cubicle were between $38 \%$ for the highest occupancy case and $65 \%$ for the lowest occupancy case. The results provide strong justification for considering smaller lighting control zones - ideally at the cubicle level.

Table 3: Example lighting simulation results at 4 pm and $7 p m$ for lighting control zones that cover four cubicles. Each white square represents a cubicle with a present occupant. Each yellow square represents a cubicle with the lights on.

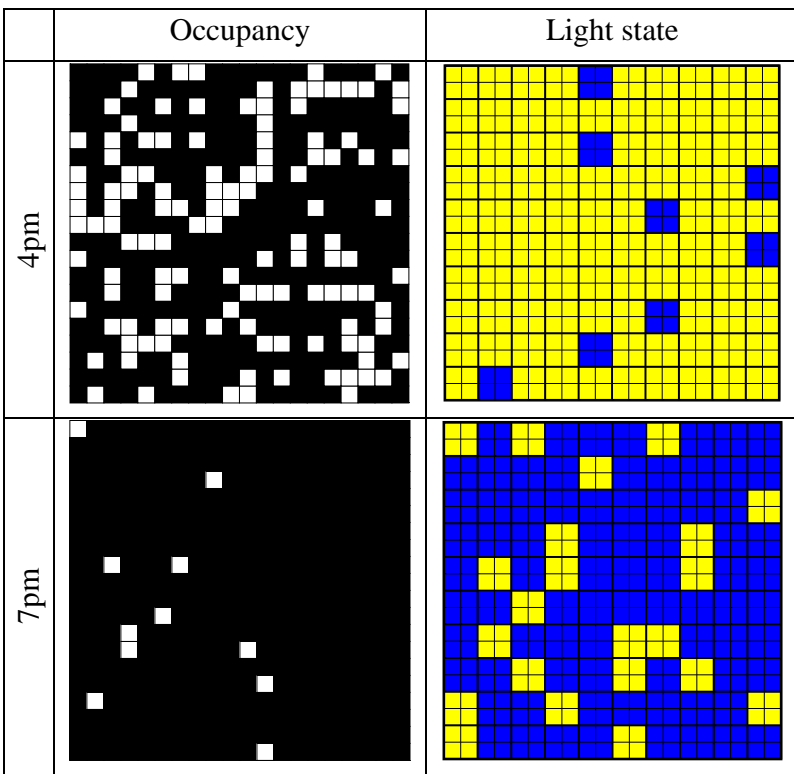

The astute reader will notice the NECB line in Figure 4 is significantly lower than the detailed simulations. This is primarily a result of early morning and evening lighting being much higher than the schedule would suggest because of the amount of lighting required for even sparse occupancy (e.g., at 7pm in Table 3).

As different occupancy scenarios are explored, it seems illogical to exclusively use a building-centric approach for quantifying performance. Instead, lighting time or energy can be normalized by occupancy as a better measure for the effectiveness of lighting utilization (O'Brien, Gaetani, Carlucci, Hoes and Hensen 2017). Thus, the results were plotted again with this new normalization scheme such that the hours that lights are on for one cubicle are divided by the number of hours that the occupant is present in that cubicle (Figure 5). This approach can be integrated over the space to obtain a building-wide value. A value of unity means that the lights are on exactly as long as the occupant is present, which is optimal for a non-daylit space. In reality, the lights stay on 20 minutes after the occupant departs, which can substantially increase lighting energy use for occupants how arrive and depart many times during the day (Gilani and O'Brien 2018). While codes typically do not consider an occupant-centric approach, the ratio of time that lights are on to occupants present according to the NECB schedules is 1.33. O'Brien, Gaetani, Carlucci, Hoes and Hensen (2017) showed that this ratio can reach two in reality even in private daylit offices.

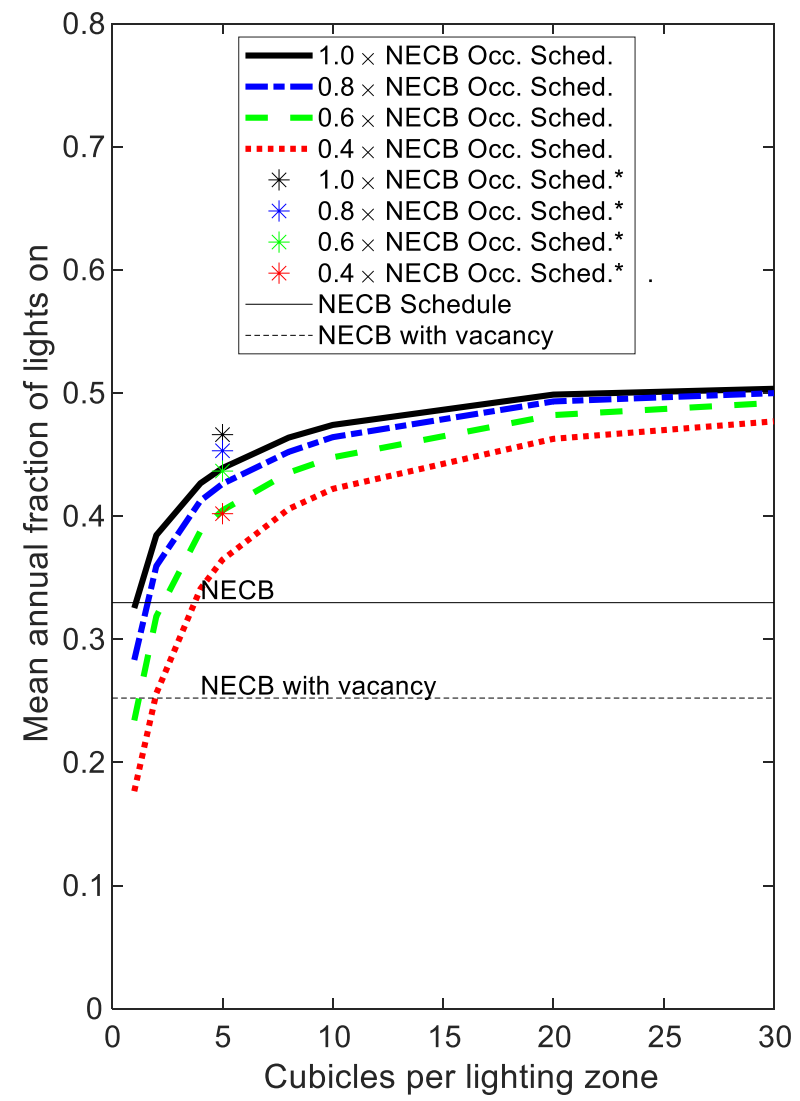

Figure 4:Lighting simulation results for lighting use as a function of occupancy schedule and lighting control zone size. The asterisks correspond to the exact NECB lighting control zone requirements (which are different for lights-on and light-off controls). Note that the simulations exceeded 25 cubicles to generate this plot.

The results for the occupant-centric lighting control strategy (Figure 5) tell a very different story to Figure 4. For the lowest occupancy scenario, the ratio of lights on to occupants present exceeds five. Even the high occupancy scenario yields a ratio of approximately two. The reason for the high values is that the lights in the entire control zone are on even if there is a single occupant within the zone or twenty minutes after they have departed. Table 3 provides an insightful example as to the significant waste. Notably, none of the occupancy scenarios with even a single cubicle per zone reaches a ratio of unity. This is because the lights remain on for 20 
minutes after departure. In contrast to what schedules might suggest, occupants routinely leave their offices five to ten times per day (Gilani and O'Brien 2018). In an extreme case of an occupant momentarily entering their office many times, the ratio of lighting to occupancy could theoretically approach infinity.

Back to the objective of this paper, Figure 5 makes strong case for reducing lighting control zones beyond current code requirements. The slope for the lines - particularly lower occupancy scenarios - are very high as the lighting control zones approach one cubicle. A high slope means that there is significant energy-saving potential by reducing lighting control zone size further.

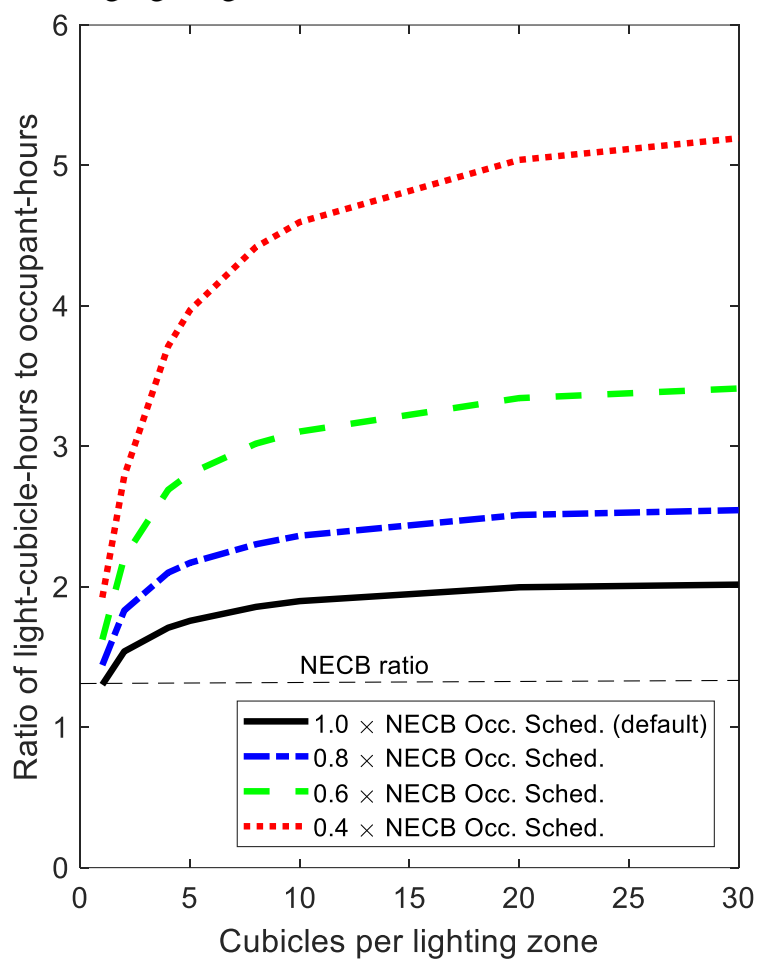

Figure 5:Lighting simulation results for lighting use expressed as the ratio of lighting to occupants

\section{DCV analysis results}

First, the maximum impact of DCV on outdoor air supply was quantified to establish expected potential of DCV to save energy. Figure 6 shows the required airflow rate (ASHRAE Std. 62.1-2016) for three cases: no DCV, DCV with the normal weekday office occupancy schedule, and DCV with no occupants. The maximum outdoor air supply savings per day is $29 \%$, which represents the difference between scheduled ventilation (based on the assumption of full occupancy in Equation 1) and ventilation required for an unoccupied (but ventilated) building. Because of the area component in Equation 1, significant outdoor air supply is still required when the occupancy is near-zero.

The above analysis provides a sense of the potential for DCV, but does not help explain how reduced airflow affects heating, cooling, and fan energy. As such, eight annual simulations of the full building were run in EnergyPlus: four occupancy levels (i.e., 1, 0.8, 0.6, and 0.4 times the NECB schedule) and with and without DCV activated. These results are summarized in Figure 7. As expected DCV is beneficial for all cases considered because of the phenomenon illustrated in Figure 6. It can be seen that the benefit of DCV nearly doubles from 2.4 to $4.5 \%$ for the standard schedule compared to the lowest occupancy scenario ( $40 \%$ of standard schedule). While these energy savings may not seem profound, this range is typical of the impact of many other energy efficiency measures that are considered during design. As such, there is a reasonably good chance that DCV would get "value engineered" out of a design on this basis.

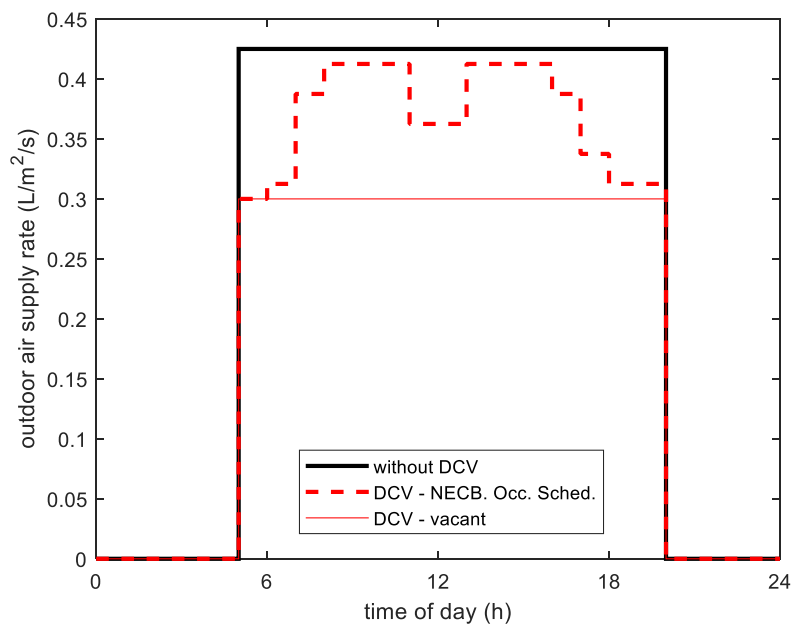

Figure 6:Lighting simulation results for lighting use expressed as the ratio of lighting to occupants

Examining the EnergyPlus results more closely, it is noteworthy that the majority of the savings is from heating energy; DCV saves between $11 \%$ (standard schedule) and $19 \%(40 \% \times$ schedule $)$. Cooling energy savings are minimal $(<1 \%)$ for two reasons: (1) the cooling energy for Toronto is relatively low compared to the heating energy, and (2) DCV has a slight adverse effect in reducing outdoor air when it would be beneficial (i.e., free cooling). These results are in line with previous findings (Fisk and De Almeida 1998). Fan energy was not significantly reduced because the VAV system uses air for both conditioning and supplying outdoor air; typically, space conditioning drives the airflow rate.

\section{Recommendations}

Given the evidence presented here that strongly suggests that the standard schedules underpredict the energysaving benefit of occupancy-adaptive technologies, this paper concludes by making some future recommendations for design practice and building codes.

First, we recommend that energy modellers consider several different occupancy scenarios during the design process. If a particular decision is sensitive to occupancy assumptions, it suggests that closer attention should be paid to estimating occupancy. If occupancy is uncertain, occupancy-adaptive technologies are a wise path forward. While O'Brien, Gaetani, Gilani, Carlucci, Hoes and Hensen (2016) reported that modellers are reluctant to admit uncertainty of energy performance predictions from simulation, we argue that such analysis and dialogue with 
clients should become standard practice - particularly in an era of changing workplace configurations.

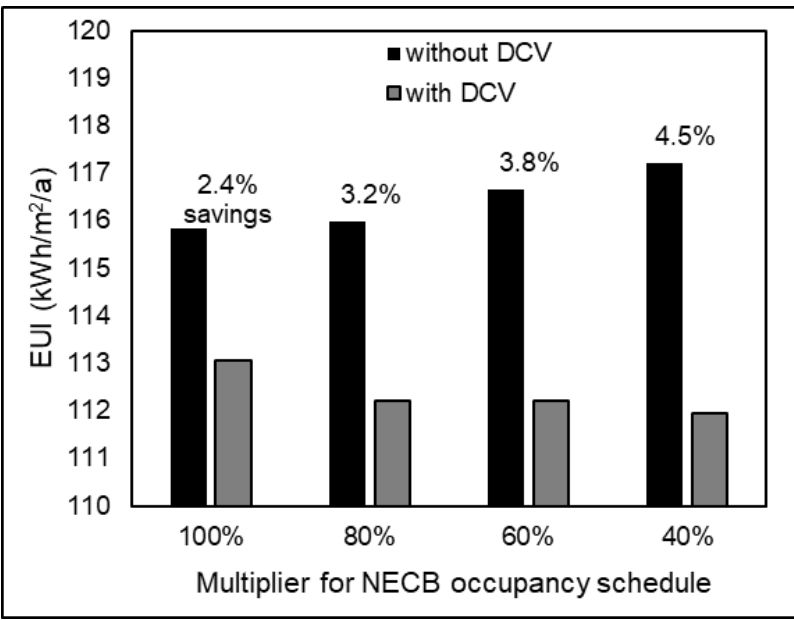

Figure 7: Total energy savings as a result of DCV for the four different occupancy scenarios. The annotated values indicate the total energy savings from $D C V$.

While altering occupancy schedules is a relatively trivial task for practitioners (and could even be automated in future BPS tools and workflows), the agent-based modelling used for the lighting analysis here would require more effort. Such a feature could be incorporated into BPS tools or merely be used to by code committees to develop new prescriptive requirements.

Building energy codes usually have two prominent paths: prescriptive and performance. Given the current findings, we recommend that code committees rerun archetype models across climates and building types to evaluate all aspects that are related to occupancy. Beyond the current paper, this could also extend to setpoint and AHU schedules. The current results suggest that lighting control zones corresponding to each cubicle or workspace would yield significant energy savings. Admittedly, this would face resistance from industry, given the additional cost. However, new technologies (e.g., power-over-Ethernet) are improving the ease of implementing high-resolution lighting controls. Moreover, these results point to significant benefit from task lighting. Task lighting also addresses the issue that overhead lighting is relatively fixed in geometry, whereas cubicle geometry may change multiple times over the life of a building.

We also recommend that DCV be mandated in more building types, given new knowledge or insights generated by simulating multiple occupancy scenarios.

For the performance path, we recommend that codes mandate the use of at least three different occupancy scenarios. Given the uncertainty of occupancy, this process would ensure that a range of plausible scenarios could be evaluated and that occupancy-adaptive technologies would be adequately rewarded. The code could require that the proposed design building beat the reference building for all cases or only that the average proposed building beat the average reference building. As noted above, BPS tools could automate this process to minimize modeller effort.

\section{Conclusion}

The aim of this paper was to investigate the significance of the risk that occupancy-adaptive building technologies are overlooked because of the standard practice to use near-full occupant schedules for simulation-aided design and the performance path of energy code compliance. To address this, two technologies were investigated: occupancy-based lighting control in open-plan offices and demand-controlled ventilation. Each technology required customized and unique approaches to model occupancy and the building, given the non-standard analysis. While the methods were simple and had limitations (e.g., daylight was ignored, it was assumed that all occupants required light directly from overhead, and occupants were assumed to be of uniform density for the entire building in the DCV analysis), they are generally expected to be adequate for the analysis of interest.

The results showed that lower occupancy levels greatly increase the benefit of smaller lighting control zones. Moreover, the low occupancy scenario resulted in lighting being on as much as five times more than occupants are present at the cubicle level. Meanwhile, the lowoccupancy scenario nearly doubled the predicted energy savings of DCV relative to the standard schedules. These results demonstrate that occupancy-adaptive technologies become much more effective when more typical occupancy schedules are considered. The results are in line with those reported by the literature (i.e. refer to literature review). However, further analysis with accurate cost information and occupancy data would be required to perform a detailed probabilistic economic analysis. Moreover, future research should focus on verifying the current results using measurements in real buildings.

Following further analysis, we recommend that:

- designers simulate multiple occupancy scenarios, like the current ones, to establish and present to clients the opportunity for occupancy-adaptive technologies and design decisions;

- code committees reassess and consider updating prescriptive requirements related to occupants and occupant-based controls based on updated schedules or a range of schedules (as was done in this paper); and,

- the performance path of future codes requires simulation of multiple occupancy scenarios with average values reported so that occupancy-adaptive technologies are adequately rewarded.

\section{Acknowledgement}

The authors acknowledge support from project partners Natural Resources Canada, RWDI, Autodesk, and National Research Council of Canada. The authors are participants of IEA EBC Annex 79.

\section{References}

Abuimara, T., W. O'Brien, B. Gunay, A. Abdelalim, M. Ouf and S. Gilani (2018). Modelling Occupants in Buildings: Stakeholders' Workshop on Current 
Barriers, Challenges and Needs. eSim 2018, Montreal, QC May 8-9.

American Society of Heating Refrigerating and Air Conditioning Engineers (ASHRAE) (2016). 62.12016, Ventilation for acceptable indoor air quality. American Society of Heating, Refrigerating and AirConditioning Engineers, Atlanta.

Bennet, I. E. and W. O’Brien (2017). "Office building plug and light loads: Comparison of a multi-tenant office tower to conventional assumptions." Energy and Buildings 153: 461-475.

Davis III, J. A. and D. W. Nutter (2010). "Occupancy diversity factors for common university building types." Energy and Buildings 42(9): 1543-1551.

de Bakker, C., M. Aries, H. Kort and A. Rosemann (2017). "Occupancy-based lighting control in openplan office spaces: A state-of-the-art review." Building and Environment 112: 308-321.

Duarte, C., K. Van Den Wymelenberg and C. Rieger (2013). "Revealing occupancy patterns in an office building through the use of occupancy sensor data." Energy and Buildings 67: 587-595.

Fisk, W. J. and A. T. De Almeida (1998). "Sensor-based demand-controlled ventilation: a review." Energy and Buildings 29(1): 35-45.

Gaetani, I., P.-J. Hoes and J. L. M. Hensen (2016). "Occupant behavior in building energy simulation: Towards a fit-for-purpose modeling strategy." Energy and Buildings 121: 188-204.

Galasiu, A. D., G. R. Newsham, C. Suvagau and D. M. Sander (2007). "Energy saving lighting control systems for open-plan offices: a field study." Leukos 4(1): 7-29.

Gilani, S. and W. O'Brien (2018). "A preliminary study of occupants' use of manual lighting controls in private offices: A case study." Energy and Buildings 159: 572-586.

Gilani, S., W. O’Brien and B. Gunay (2018).

"Simulation of occupants' impact at different spatial scales." Building and Environment 132(3): 327-337.

Gilani, S., W. O’Brien, H. B. Gunay and J. S. Carrizo (2016). "Use of dynamic occupant behavior models in the building design and code compliance processes." Energy and Buildings 117(1): 260-271.

Gunay, H. B., W. O'Brien and I. Beausoleil-Morrison (2015). "Development of an occupancy learning algorithm for terminal heating and cooling units." Building and Environment 93, Part 2: 71-85.
Hong, T. and W. J. Fisk (2010). "Assessment of energy savings potential from the use of demand controlled ventilation in general office spaces in California." Building Simulation 3: 117-124.

Hood, C., G. Nagy, K. Lister and J. Brand (2017). 2017 State of Telecommuting in the U.S. Employee Workforce: 65 .

Liu, G., J. Zhang and A. Dasu (2012). "Review of literature on terminal box control, occupancy sensing technology and multi-zone demand control ventilation (DCV)." US Department of Energy, Tech. Rep.

Nassif, N. (2012). "A robust CO2-based demandcontrolled ventilation control strategy for multi-zone HVAC systems." Energy and Buildings 45: 72-81.

O'Brien, W., I. Gaetani, S. Carlucci, P.-J. Hoes and J. L. M. Hensen (2017). "On occupant-centric building performance metrics." Building and Environment 122: 373-385.

O’Brien, W., I. Gaetani, S. Gilani, S. Carlucci, P.-J. Hoes and J. Hensen (2016). "International survey on current occupant modelling approaches in building performance simulation." Journal of Building Performance Simulation: 1-19.

O’Brien, W., H. B. Gunay, F. Tahmasebi and A. Mahdavi (2017). "A preliminary study of representing the inter-occupant diversity in occupant modelling." Journal of Building Performance Simulation 10(5-6): 509-526.

Page, J., D. Robinson, N. Morel and J.-L. Scartezzini (2008). "A generalised stochastic model for the simulation of occupant presence." Energy and Buildings 40(2): 83-98.

Reinhart, C. F. and K. Voss (2003). "Monitoring manual control of electric lighting and blinds." Lighting Research \& Technology 35(3): 243-260.

Schweiker, M., F. Haldi, M. Shukuya and D. Robinson (2012). "Verification of stochastic models of window opening behaviour for residential buildings." Journal of Building Performance Simulation 5(1): 55-74.

Shen, W., G. Newsham and B. Gunay (2017). "Leveraging existing occupancy-related data for optimal control of commercial office buildings: A review." Advanced Engineering Informatics 33: 230242.

Tahmasebi, F. and A. Mahdavi (2015). "The sensitivity of building performance simulation results to the choice of occupants' presence models: a case study." Journal of Building Performance Simulation: 1-11. 